\title{
Prolonged Hemiplegic Migraine Associated with Irreversible Neurological Deficit and Cortical Laminar Necrosis in a Patient with Patent Foramen Ovale $\triangle A$ case report
}

\author{
Yacen $\mathrm{Hu}$ \\ Xiangya Hospital Central South University https://orcid.org/0000-0002-1199-4659 \\ Zhiqin Wang \\ Xiangya Hospital Central South University \\ Lin Zhou \\ Xiangya Hospital Central South University \\ Qiying Sun ( $\nabla$ sunqiying2015@163.com) \\ Xiangya Hospital, Central South University https://orcid.org/0000-0002-2031-8345
}

\section{Case report}

Keywords: Hemiplegic migraine, irreversible neurological deficit, cortical laminar necrosis, patent foramen ovale, case report

Posted Date: April 30th, 2021

DOI: https://doi.org/10.21203/rs.3.rs-439782/v1

License: @ (1) This work is licensed under a Creative Commons Attribution 4.0 International License. Read Full License 


\section{Abstract}

Background: Aura symptoms of hemiplegic migraine (HM) usually resolve completely, permanent attack-related deficit and radiographic change are rare.

Case presentation: We reported a HM case presented with progressively aggravated hemiplegic migraine episodes refractory to medication. He experienced two prolonged hemiplegic migraine attacks that led to irreversible visual impairment and cortical laminar necrosis (CLN) on brain MRI. Patent foramen ovale (PFO) was found on the patient. PFO closure resulted in a significant reduction of HM attacks.

Conclusions: Prolonged hemiplegic migraine attack could result in irreversible neurological deficit with neuroimaging changes manifested as CLN. We recommend screening for PFO in patients with prolonged or intractable hemiplegic migraine, for that closure of PFO might alleviate the attacks thus preventing patient from disabling sequelae.

\section{Background}

Hemiplegic migraine (HM) is characterized by aura of motor weakness accompanied by visual, sensory, and/or speech symptoms followed by migraine headache[1]. According to International Classification of Headache Disorders, 3rd edition (ICHD-3) criteria, aura of HM should be fully reversible [2]. Though little is known about imaging manifestations during HM attack, swelling and/or cortical hyperintensity on T2/FLAIR-weighted MRI images have been described, which were mostly reversible after attack resolution [1].

Studies have reported a bidirectional association between patent foramen ovale (PFO) and migraine[3].Percutaneous PFO closure has been reported to reduce the burden of migraineurs with PFO[4]. Report of PFO closure in patients with HM is rare.

We described a case of a 53-year-old man with progressively aggravated hemiplegic migraine episodes with age. The patient suffered two prolonged attacks led to irreversible visual impairment and cortical laminar necrosis (CLN) on brain MRI. Patent foramen ovale (PFO) was found on the patient. PFO closure resulted in a significant reduction of HM attacks

\section{Case Presentation}

A 53-year-old man was admitted to our hospital because of severe left-sided headache for one week. He reported a long history of migraine with aura since childhood. The migraine was always preceded by aura of hemiparesis and hemianesthesia. Severe pulsating headache started 20 minutes after aura, lasting for hours with photophobia and vomiting. Aura completely resolved 30 minutes after headache onset. The attacks were usually triggered by colds, fatigue,insufficient sleep, or mental stress with a frequency of approximately one episode per year. Since age 20 , the episode aggravated with increased frequency (7-8 attacks per year), prolonged headache (24 48 hours), additional visual aura symptom and prolonged aura duration (hours, sometimes days after headache resolution). At the age of 51 , he suffered the first severe prolonged attack. Aura started with weakness and numbness in the left side and followed by left visual field defect and subsequently headache. Brain MRI in acute phase showed right temporal-parietal-occipital cortical edema with restricted diffusion. Symptoms lasted for 3 weeks with incomplete recovery of visual impairment, leaving left visual field defect. Repeated MRI performed 4 weeks after symptom onset showed hyperintensity on T1-weighted image in right occipitaltemporal cortex, suggestive of CLN (Fig. 1).

The second prolonged attack occurred one week before administration to our hospital. Weakness and numbness appeared in the right side accompanied by speech disturbances. Headache appeared 10 minutes after the aura onset. Neurological symptoms deteriorated with aphasia, confusion and visual impairment presented the next day. Headache and aura symptoms persisted without resolution and refractory to ibuprofen and tramadol.

On administration, the patient was afebrile with normal vital signs. Neurological examination showed mild decreased alertness, rightsided paresis and paresthesia, mixed aphasia and bilateral visual field defect predominately in the right side. Routine laboratory testing from blood and urine samples were normal. Plasma lactate acid level was within normal limit. Tests for autoimmune and infectious diseases were negative. Lumber puncture showed normal intracranial pressure. Cerebrospinal fluid examination was negative. Electroencephalogram (EEG) showed nonepileptic-form with diffuse slowing over the left hemisphere. Brain MRI performed 10 days after the episode onset showed hyperintensity of the right temporal-parietal-occipital cortex on T2-FLAIR images with gyriform enhancement and diffusion restriction. MRA demonstrated vasodilation of the branches of the left middle cerebral artery (MCA) and 
posterior cerebral artery (PCA) (Fig. 2). Transthoracic echocardiography revealed the presence of PFO. Mitochondrial DNA and whole exon sequence of nuclear DNA were analyzed by targeted region capture and high-throughput sequencing, but failed to detect any significant variant.

The patient was diagnosed as hemiplegic migraine and was treated with diclofenac, flunarizine, topiramate, and glycerine fructose. The headache relieved slightly, but aura persisted without resolution. On day 15 since the episode onset, headache deteriorated with aggravated limb weakness and worsened consciousness. Repeated brain MRI revealed aggravated cortical edema involving entire left hemisphere. MRA showed prominent vasodilation of left MCA and PCA while PWI showed hyperperfusion in corresponding region (Fig. 3). Headache and neurological symptoms gradually improved during the next two weeks and the patient was discharged on a prophylactic dose of lunarizine and topiramate.

During the following two months, HM episode recurrent 4 times though patient adhered to the prophylaxis. Two months later, the patient was hospitalized again and a percutaneous procedure of PFO closure was performed successfully. The patient experienced pronouncedly less frequent episodes of headache after the PFO closure, without taking any prophylactic medication for migraine. On 12-month follow-up, he reported only two episodes of mild headache with mild weakness and numbness lasting for less than 3 hours. However, visual impairment did not resolve completely in bilateral visual field.

\section{Discussion And Conclusions}

Aura symptoms of $\mathrm{HM}$ usually fully resolve within 24 hours. Though cases with slow recovery that neurological symptoms lasted up to weeks and months have been described, permanent attack-related deficit was rare. Several case reports showed diffusive or hemispheric cortical edema with diffusion restriction during acute phase of HM attacks, which were mostly reversible after attack resolution. To our knowledge, only 2 cases reported attack-related permanent sequelae and irreversible neuroimaging changes $[5,6]$. Our patients, who had a long history of recurrent attacks of HM, developed irreversible visual deficits as a result of two prolonged attacks that were associated with neuroimaging changes manifested as CLN.

CLN is a permanent injury characterized by selective necrosis of the cerebral cortex. It is generally caused by severe long-lasting cerebral metabolism impairment and energy depletion. Image features of CLN are characterized by gyriform hyperintensity of the cerebral cortex on FLAIR and gadolinium-enhanced images in acute phase. Hyperintensity on T1-weighted images often appears 2 weeks after the events and may last up to 2 years[7].In our patient, the gyriform enhancement and hyperintensity on FLAIR and T1-weighted images were consistent with the characteristics of CLN.

CLN has been reported in both convulsive and non-convulsive epilepsy status as well as in mitochondrial encephalopathy, which should be considered as differential diagnosis for this patient. Epileptic status was ruled out for the absence of clinical symptoms/signs, lack of epileptic-like discharge on long-term EEG and irresponsiveness to antiepileptic drug. Mitochondrial encephalopathy was not considered based on normal serum lactate level, absence of other clinical features, and negative genetic tests.

CLN has also been reported in migrainous infarction[8], an uncommon complication of migraine with aura, defined as cerebral ischemic infarction occurs during the attack of migraine with aura. However, it is questionable to ascribe the clinical and imaging changes of our patient as migrainous infarction. First, though PFO was found in our patient, the imaging features did not conform to the typical manifestations of paradoxical cerebral embolism. Second, diffusion restriction seen in our patient is milder compared to typical acute cerebral infarction. More importantly, deterioration of neurological symptoms and aggravation of brain edema were associated with persistent vasodilation and hyperperfusion in the affected hemisphere during the second prolonged attack, suggesting that ischemia is probably not the main factor leading to prolonged symptoms and cerebral edema.

The mechanism underlying vasodilatation and hyperperfusion remains unknown. One hypothesis suggested that vasodilation was caused by increased energy demand due to intrinsic neuron activation during prolonged HM attack. When cerebral perfusion is not sufficient, energy depletion and metabolites accumulation occur, leading to hypermetabolic neural necrosis. Another hypothesis speculated that vasodilatation is caused by impaired cerebral artery autoregulation. Persistent vasodilatation could lead to hyperperfusion brain damage, which could result in brain edema and CLN on MRI [9].

Another intriguing aspect in our case was the presence of a PFO. Observational studies suggested that PFO closure may reduce migraine attacks [4]. Due to the rarity of HM, only 3 cases reporting the closure of PFO in HM patients. All of the 3 patients had partial or complete relief of attacks after PFO closure (Table 1) [10-12]. In our case, frequency and severity of attacks increased with age and was 
refractory to medication before PFO closure. Surprisingly, the patient had remarkably reduced HM attacks after PFO closure without taking prophylactic medication. Our case added to the evidence that HM patient with PFO might benefit from PFO closure. However, in the natural history of $\mathrm{HM}$, gradual relieve at adulthood or long interval without attacks could occur unpredictably, which we could not rule out in our case. Moreover, we noticed that migraine attacks may not cease completely after PFO closure in our case and previous reported cases, suggesting that PFO was not the only factor contributing to HM attacks.

Table 1

Summary of hemiplegic migraine cases with PFO

\begin{tabular}{|c|c|c|c|c|c|c|c|c|}
\hline Reference & SHM/FHM & $\begin{array}{l}\text { Age/ } \\
\text { onset } \\
\text { age }\end{array}$ & Sex & $\begin{array}{l}\text { Frequency } \\
\text { of attacks }\end{array}$ & $\begin{array}{l}\text { Prolonged } \\
\text { attack }\end{array}$ & Aura & Neuroimaging & $\begin{array}{l}\text { Prognosis after PFO } \\
\text { closure }\end{array}$ \\
\hline [10] & SHM & $14 / 13$ & Male & ND & 口 & $\begin{array}{l}\text { Visual } \\
\text { disturbances, } \\
\text { alternating } \\
\text { hemiplegia, } \\
\text { dysarthria, } \\
\text { confusion }\end{array}$ & $\begin{array}{l}\text { Normal MRI } \\
\text { and MRA }\end{array}$ & $\begin{array}{l}\text { Complete remission of } \\
\text { attacks for } 3 \text { years on } \\
\text { follow up without any } \\
\text { medication }\end{array}$ \\
\hline [11] & SHM & $35 / 33$ & Male & ND & प & $\begin{array}{l}\text { Slurred } \\
\text { speech, } \\
\text { dizziness, } \\
\text { diplopia, } \\
\text { paresthesia, } \\
\text { hemiparesis }\end{array}$ & $\begin{array}{l}\text { Normal MRI } \\
\text { during attack. } \\
\text { MRA showed } \\
\text { hypoplasia of } \\
\text { basilar artery }\end{array}$ & $\begin{array}{l}\text { Complete remission of } \\
\text { attacks for 4-year after } \\
\text { PFO closure. Five years } \\
\text { later, the attacks } \\
\text { relapsed with a mild re- } \\
\text { opening of PFO. }\end{array}$ \\
\hline [12] & $\begin{array}{l}\text { SHM with } \\
\text { a } A T P 1 A 2 \\
\text { variant } \\
\text { (R937L) }\end{array}$ & $19 / 9$ & Male & 10/year & - & $\begin{array}{l}\text { Scintillating } \\
\text { scotomas, } \\
\text { paresis and } \\
\text { paresthesia, } \\
\text { speech } \\
\text { disturbances }\end{array}$ & Normal & $\begin{array}{l}\text { Marked reduced attacks } \\
\text { in } 12 \text { months following } \\
\text { the PFO closure; } \\
\text { complete remission at } \\
\text { least in the following } 24 \\
\text { months. }\end{array}$ \\
\hline Present & SHM & $53 / 9$ & Male & 7-8/year & प & $\begin{array}{l}\text { Visual field } \\
\text { defect, } \\
\text { paresis and } \\
\text { paresthesia, } \\
\text { speech } \\
\text { disturbances, } \\
\text { confusion }\end{array}$ & $\begin{array}{l}\text { Cortical } \\
\text { edema, } \\
\text { vasodilation } \\
\text { and } \\
\text { hyperperfusion } \\
\text { during attack, } \\
\text { followed by } \\
\text { CLN }\end{array}$ & $\begin{array}{l}\text { Marked reduced attacks } \\
\text { on } 12 \text {-months follow up } \\
\text { after PFO closure } \\
\text { without } \\
\text { prophylactic medication }\end{array}$ \\
\hline
\end{tabular}

SHM, sporadic hemiplegic migraine; FHM, familial hemiplegic migraine; ND: not described.

This peculiar case indicates that prolonged hemiplegic migraine attack, though rare, could result in irreversible neurological deficit with neuroimaging changes manifested as CLN. Closure of PFO might alleviate the attacks, thus preventing patient from disabling sequelae. The association between PFO and HM, and the efficacy of PFO closure in HM need to be confirmed in randomized controlled studies. Even thought, for patients with prolonged or intractable hemiplegic migraine, screening for PFO is recommended as patients might benefit from the closure of PFO.

\section{Abbreviations}

HM: hemiplegic migraine; MRI: Magnetic Resonance Imaging; CLN: cortical laminar necrosis; PFO: patent foramen ovale; ICHD-3: International Classification of Headache Disorders, 3rd edition; DWl: diffusion weighted imaging; PWI: perfusion weighted imaging; MRA: magnetic resonance angiography; FLAIR: fluid attenuated inversion recovery; EEG: Electroencephalogram; MCA: middle cerebral artery; PCA: posterior cerebral artery; DNA: deoxyribonucleic acid; CBF: cerebral blood flow; CBV: cerebral blood volume.

\section{Declarations}

\section{Authors' contributions}

YH and ZW collected the clinical data, reviewed the literature, and drafted the manuscript. QS and LZ designed the study, oversaw data acquisition, supervised the initial drafting, and critically revised the manuscript. The authors read and approved the final manuscript. 


\section{Ethics approval and consent to participate}

Written informed consent for publication of their clinical details and/or clinical images was obtained from the relative of the patient.

\section{Availability of data and material}

The data that support the findings of this case series are available from the corresponding author on reasonable request.

\section{Acknowledgments}

The authors received no financial support for the research, authorship, and/or publication of this article.

\section{Funding}

This work was supported by grants from the National Natural Science Foundation of China (81401060) and Natural Science Foundation of Hunan Province, China (2020JJ5927).

\section{Conflict of Interest}

The authors declare no conflict of interest.

\section{References}

1. Di Stefano V, Rispoli MG, Pellegrino N, Graziosi A, Rotondo E, Napoli C, Pietrobon D, Brighina F, Parisi P (2020) Diagnostic and therapeutic aspects of hemiplegic migraine. J Neurol Neurosurg Psychiatry 91:764-771

2. Headache Classification Committee of the International Headache Society (IHS) The International Classification of Headache Disorders, 3rd edition. Cephalalgia 2018, 38:1-211

3. Takagi H, Umemoto T, Group A (2016) A meta-analysis of case-control studies of the association of migraine and patent foramen ovale. J Cardiol 67:493-503

4. Slavin L, Tobis JM, Rangarajan K, Dao C, Krivokapich J, Liebeskind DS (2007) Five-year experience with percutaneous closure of patent foramen ovale. Am J Cardiol 99:1316-1320

5. Cha YH, Millett D, Kane M, Jen J, Baloh R (2007) Adult-onset hemiplegic migraine with cortical enhancement and oedema. Cephalalgia 27:1166-1170

6. Black DF, Kung S, Sola CL, Bostwick MJ, Swanson JW (2004) Familial hemiplegic migraine, neuropsychiatric symptoms, and Erdheim-Chester disease. Headache 44:911-915

7. Siskas N, Lefkopoulos A, loannidis I, Charitandi A, Dimitriadis AS (2003) Cortical laminar necrosis in brain infarcts: serial MRI. Neuroradiology 45:283-288

8. Morais R, Sobral F, Cunha G, Brito O, Santana I (2018) Advanced MRI study of migrainous infarction presenting as cortical laminar necrosis - Case report and literature review. Clin Neurol Neurosurg 167:82-85

9. Kai Y, Hamada J, Morioka M, Yano S, Mizuno T, Ushio Y (2003) Postoperative hyperperfusion in a patient with a dural arteriovenous fistula with retrograde leptomeningeal venous drainage: case report. Neurosurgery 53:228-232; discussion $232-223$

10. Brighina F, Gurgone G, Gaglio RM, Palermo A, Cosentino G, Fierro B (2009) A case of atypical sporadic hemiplegic migraine associated with PFO and hypoplasia of vertebro-basilar system. J Headache Pain 10:303-306

11. Lemka M, Pienczk-Reclawowicz K, Pilarska E, Szmuda M (2009) Cessation of sporadic hemiplegic migraine attacks after patent foramen ovale closure. Dev Med Child Neurol 51:923-924

12. Perrotta A, Gambardella S, Ambrosini A, Anastasio MG, Albano V, Fornai F, Pierelli F (2018) A Novel ATP1A2 Gene Variant Associated With Pure Sporadic Hemiplegic Migraine Improved After Patent Foramen Ovale Closure: A Case Report. Front Neurol 9:332

\section{Figures}



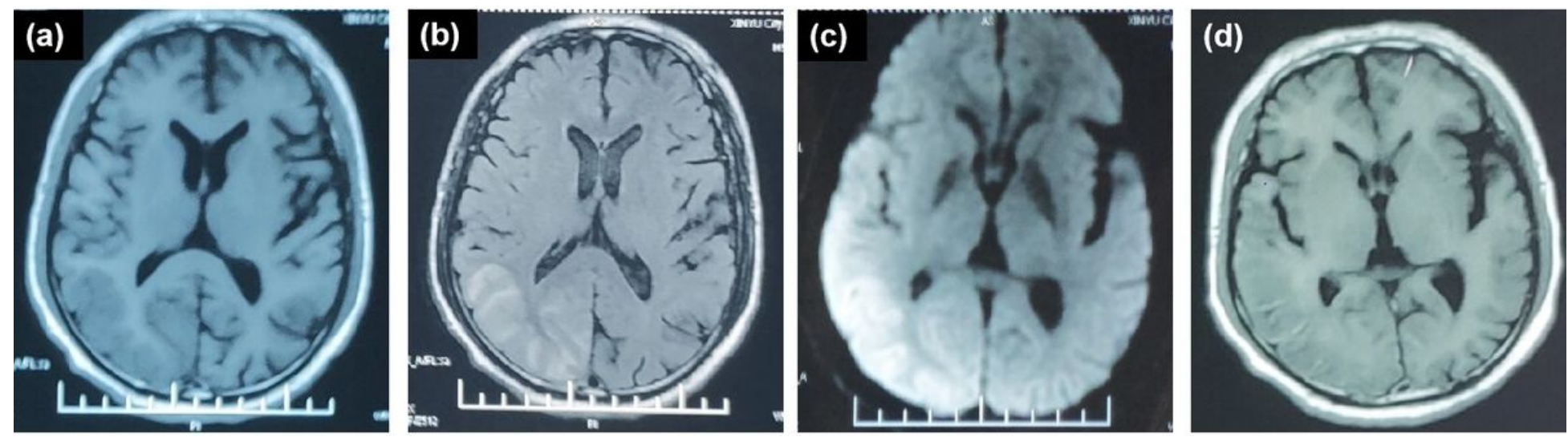

Figure 1

MRI findings in the first prolonged attack. During the acute phase, MRI demonstrates right tempro-occipital lobe hypointensity on T1weighted image (a) and hyperintensity on T2-FLAIR image (b) with restricted diffusion on DWI (c). MRI performed 4 weeks after symptom onset demonstrated right temporal-occipital cortical hyperintensity on T1-weighted images (d).
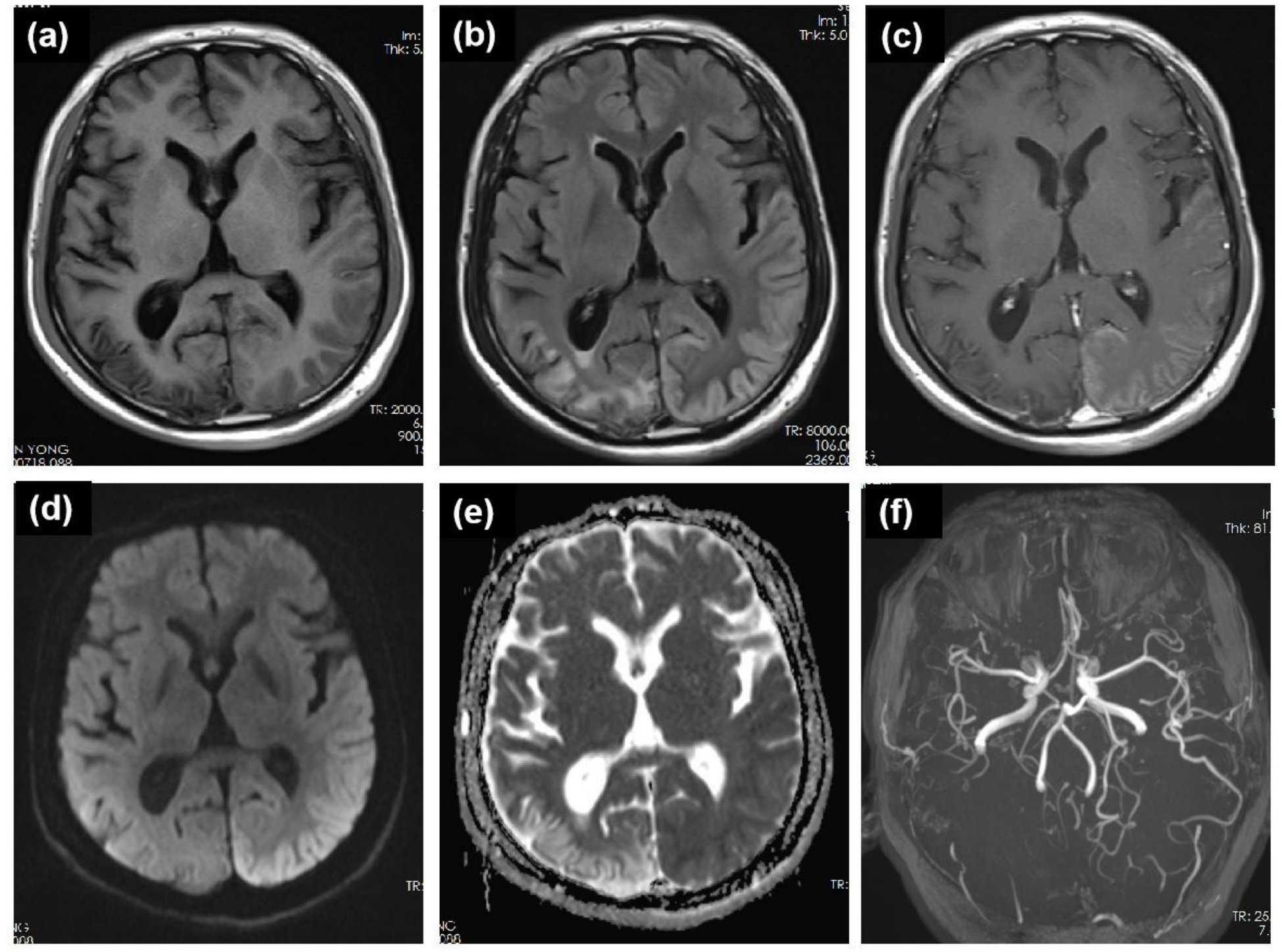

\section{Figure 2}

MRI performed 10 days after onset of the second prolonged attack. Right temporal-occipital hyperintensity on T1-weighted images (a) with gliosis on T2-FLAIR images (b) suggest the chronic stage of CLN caused by first prolonged attack. Left temporal-occipital cortex 
hyperintensity on T2-FLAIR images (b) with gyriform enhancement (c), restricted diffusion (d) and slightly decreased ADC values (e), suggest the acute stage of CLN caused by second prolonged attack. MRA demonstrated vasodilation of the branches of the left middle cerebral artery (MCA) and posterior cerebral artery (PCA) (f).
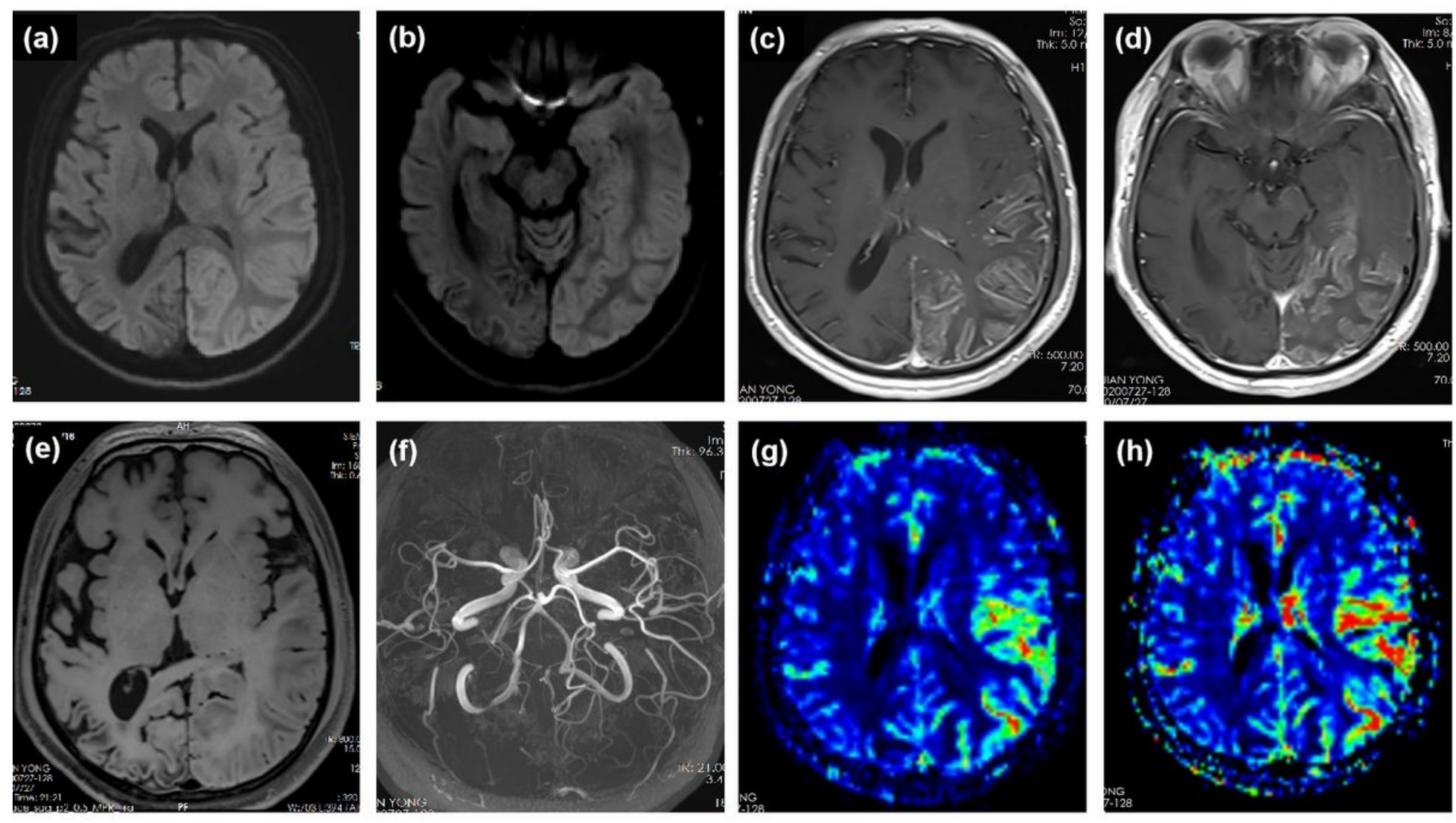

\section{Figure 3}

MRI performed 15 days after the onset of the second prolonged attack. DWI showed extensive cortical edema with diffusion restriction involving left hemisphere ( $a$ and b). Gadolinium-enhanced T1-weihgted images showed gyriform enhancement (c and d). T1-weihgted images showed slightly hyperintensity in left temporal-occipital lobe and volume loss of right temporal-occipital lobe, suggestive of subacute and chronic stage of CLN respectively (d). MRA showed dilation of left MCA and PCA (f). PWI showed increased cerebral blood flow (CBF) (g) and cerebral blood volume (CBV) (h) in left temporal-occipital lobe. 